\title{
Lymphatic Filariasis Profile in Dumka District of Jharkhand, India
}

\author{
Vikas Oraon', Vidushi Topno ${ }^{2}$ \\ ${ }^{1}$ Ass. Professor, Department of Microbiology, Phulo Jhano Medical College, Dumka. \\ ${ }^{2}$ Tutor, Department of Microbiology, Phulo Jhano Medical College, Dumka.
}

Corresponding Author: Vidushi Topno

\begin{abstract}
Lymphatic filariasis is a mosquito born disease infecting over 120 million people globally. This is a community based cross-sectional study done to assess the prevalence of disease in Dumka District of Jharkhand. Three years data (20182020) were used to know the disease spectrum in this region. The disease mostly presented itself in its chronic forms. Prevalence of the disease has decreased in three years duration. Lymphedema cases were predominant as it was seen in both male and female. The study showed Lymphedema cases as $52 \%$ in $2018,88 \%$ in 2019 and $98 \%$ in 2020. Overall disease is significantly higher in males than in female. But, Elephantiasis is more frequent in females. Present study reveals that there is remarkable impact of ELF program showing significant reduction in number of cases in three years duration. But the study indicates that the disease still continues to be the major cause of disability and poverty.
\end{abstract}

Keywords: Lymphatic filariasis, Mass drug administration, Elimination of Lymphatic Filariasis

\section{INTRODUCTION}

Lymphatic filariasis, is a neglected tropical disease transmitted to humans through mosquitoes. It causes visible disfiguring manifestations along with physical disability, mental and social suffering added with financial loses leading to poverty. ${ }^{1}$

Lymphatic filariasis is prevalent globally and is a high burden Neglected tropical disease (NTD). ${ }^{2}$ There are 120 million infected people and one billion at risk, as estimated by WHO. ${ }^{3}$ In terms of long-term disability it is the second most common cause after mental illness according to $\mathrm{WHO} .^{4,5}$

In India it is a serious health problem affecting 256 districts of 16 states and 5 union territories. Among infected people one-third live in India, a third in Africa and rest in South-East Asia, Americas, the Pacific Islands, Papua New Guinea. ${ }^{6}$

This disease is caused by roundworm nematode affecting lymphatic system and causing its damage, leading to deformities of body organs. There are eight human filarial parasites, of which Wuchereria bancrofti, B. malayi and B. Timori are involved with lymphatic system. $^{7-9}$ The primary vectors of LF in India are Culex quinquefasciatus mosquitoes. ${ }^{10}$

Debilitation caused due to chronic form of the disease leads to restriction in economic productivity. ${ }^{11}$ Women and children become more vulnerable to HIV/AIDS, tuberculosis and malaria due to helminthic diseases like LF. ${ }^{12}$ Legs and genitals are the main affected organs resulting elephantiasis and hydrocele in males and in female as breast filariasis. ${ }^{13}$ In Indian local language the disease is known as 'Hathipaon' ${ }^{14}$

$$
\text { WHO in May } 1997 \text { passed }
$$
elimination of lymphatic filariasis (ELF). The global program of ELF (GPELF) consists of mass drug administration 
(MDA), integrated vector management (IVM), morbidity management and disability prevention (MMDP) ${ }^{15,16}$. GPELF was launched in 2000 to eliminate the disease as a public health problem. The aim is to achieve the goal by annual single dose mass drug administration (MDA). This programme consists of two components that is interruption of transmission to prevent the disease by MDA and lighten the morbidity associated with the disease. Essential package of case, for every person with associated chronic manifestations of lymphatic filariasis is provided by GPELF. Measures such as insecticide treated nets, indoor residual spraying or personal protection measures may help in protection from infection. ${ }^{17}$

Dumka District is a sub-capital of Jharkhand state, India. It is a Santhal Pargana region, a famed tribal region. Total area consists of $3761 \mathrm{Sq}$. Km. with average elevation of 137 metres (449 feet). Dumka has humid subtropical climate with warm, wet summers and mild winters. It is bounded by hills, forests and rivers. Forest covers 120763 Acres of Dumka town area. ${ }^{18}$ Cases of Lymphatic filariasis are observed in Dumka district. Present study is done to assess the Lymphatic Filariasis prevalence in Dumka from 2018 to 2020 and to know the disease trend in this region.

\section{MATERIAL AND METHODS}

The present study was a community based cross-sectional study which was carried out in 10 Blocks of District Dumka, Jharkhand, India. This study was executed in Phulo Jhano Medical College, Dumka, Department of Microbiology. All cases of Lymphatic Filariasis in Dumka District from the year 2018-2020 were included. The study period was of three years duration. All cases were confirmed from line-list of the District Vector Borne Disease Control Office (DVBDCO), Dumka. There were 10 Blocks which came under District Dumka (Dumka Sadar, Jama, Shikaripara, Ranishwer, Masalia, Kathikund,
Gopikander, Ramgarh, Jarmundi and Saraiyahat).

Variables like age, sex, parts involved, lymphedema \& hydrocele, morbidity management date, date of diagnosis, treatment history, date of completion of treatment were used to assess the situation of disease in Dumka District. All the data were stored on an Excel spread sheet using Microsoft Office. Proper statistical parametric and non-parametric tests were applied depending upon the data. All the statistical analysis and graph preparations (bar and line graphs) were performed using Excel and SPSS 20.0.

\section{RESULT}

During the clinical examination in the study population, lymphatic filariasis presented mostly in its chronic form i.e. lymphedema and hydrocele. Lymphedema was recorded as $52 \%$ in 2018, $88 \%$ in 2019 and $98 \%$ in 2020. Hydrocele was recorded as $48 \%$ in 2018, 12 \% in 2019 and $2 \%$ in 2020. The study revealed that lymphedema was more prevalent than hydrocele. The study showed highest number of cases in 2018 which was 3931 cases, in 2019 there were 67 cases and in 2021 there were 61 cases.

From the affected study population male were $74 \%$ in 2018, $68 \%$ in 2019 and $53 \%$ in 2020. Female were $26 \%$ in 2018, 32 $\%$ in 2019 and $47 \%$ in 2020. Overall, lymphatic filariasis was more prevalent in males. In males the disease mainly presented as hydrocele in comparison to lymphedema. In females lymphedema mainly presented as elephantiasis. In the year 2018 lymphedema was observed in 68\% female and 32\% male, in 2019 there were $50 \%$ female and $50 \%$ male and in 2020 there were 51\% female and 49\% male. The age group maximum affected in 2018 was $41-50$ years whereas in the years 2019 and 2020 the age group maximum affected was 31-40 years. Overall, highest number of cases were discovered in Shikaripara Block followed by Jama block 
and Shikaripara. Lowest number of cases were seen in Dumka Sadar block.

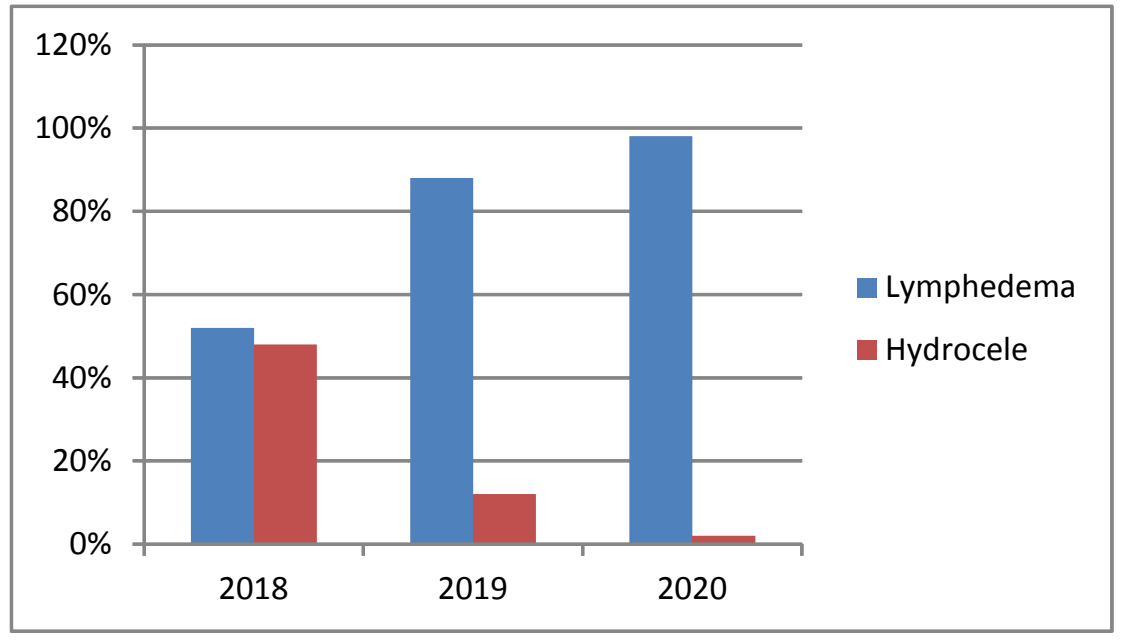

Fig-1 Prevalence of Lymphedema and Hydrocele

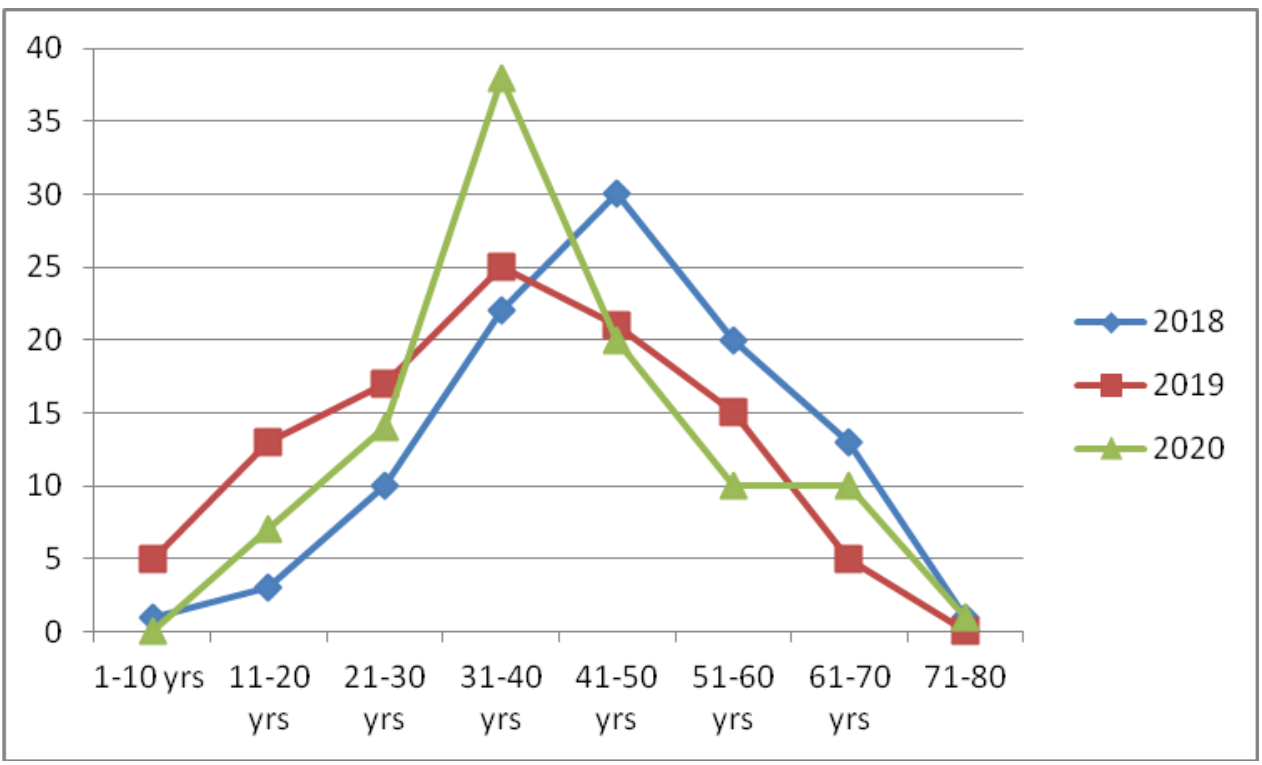

Fig -2 Age group affected with Lymphatic Filariasis

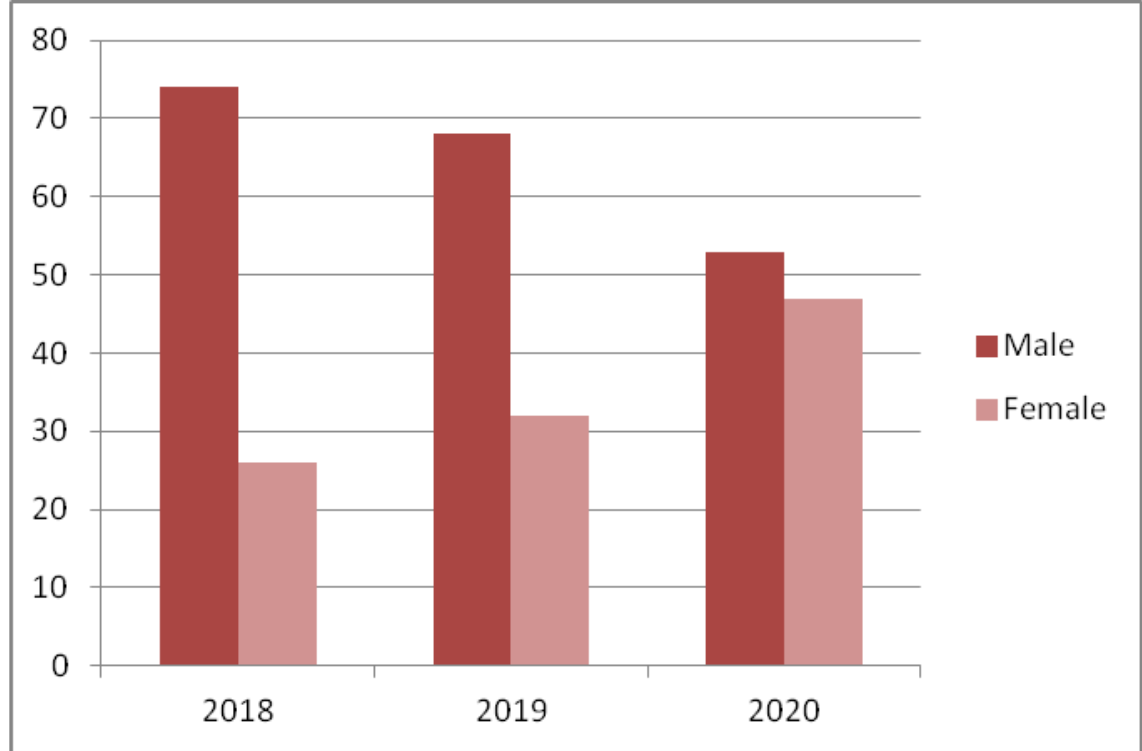

Fig-3 Male Female ratio among Lymphatic Filariasis cases 


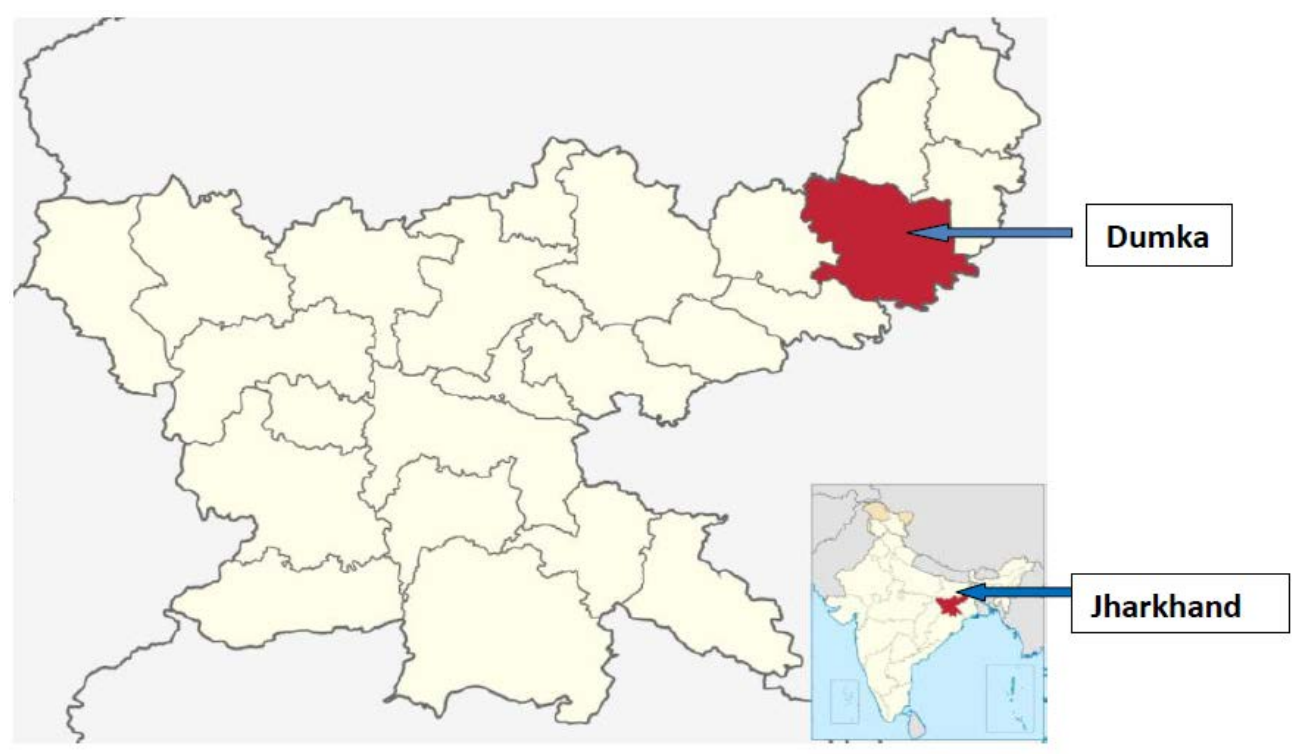

Fig. 4 Map of India showing the study area Dumka, Jharkhand.

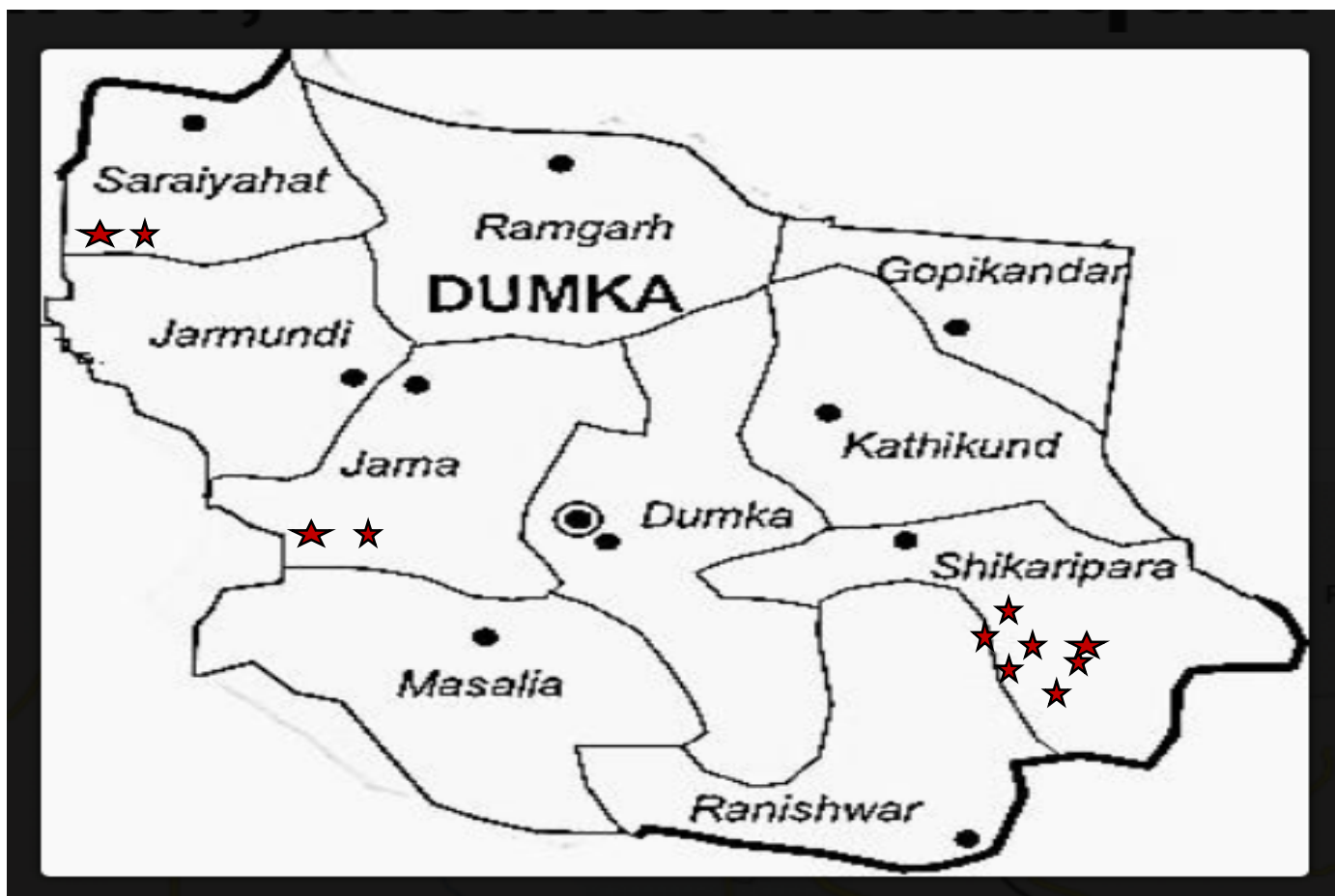

Fig-5 Dumka District with 10 BLOCKS , showing prevalence of Lymphatic filariasis. t. Prevalence of lymphatic filariasis in the year 2020 .

\section{DISCUSSION}

This was the first study done in Dumka District to evaluate the prevalence of Lymphatic Filariasis. The present study indicates that there was significant reduction in prevalence of Lymphatic filariasis from 2018 to 2020 but still continues to be a major health problem causing disability and poverty in Dumka District, Jharkhand.

The disease burden was higher in males than in females. Similar findings were seen in Pani et al (1991). ${ }^{19}$ Lymphedema and hydrocele were the major chronic forms prevalent in the study population. The number of hydrocele cases reduced every year, due to morbidity management like surgery. The prevalence of various forms of Lymphatic filariasis differs between male and female. Among chronic form of disease, the prevalence of elephantiasis was more prevalent in females. In males prevalence of hydrocele was higher than that of 
elephantiasis. Similar results were seen in (Pani et al,1991,Sharma et al,1987;). ${ }^{19,20}$

Higher prevalence of disease in males indicated higher exposure of males to mosquito bites along with other anatomical and hormonal differences between males and females. Physiological factors such as hormones have been suspected of affecting parasite establishment in human host (Brabin,1990). ${ }^{21}$

The study was done in 10 Blocks of Dumka District. Maximum number of cases were detected in Shikaripara Block followed by Jama Block and Shikaripara. Least number of cases were seen in Dumka Sadar Block.

\section{CONCLUSION}

The prevalence of Lymphatic Filariasis has decreased in Dumka District since 2018 to 2020.The present findings suggests that the study population including the high risk groups, have benefitted from ELF Program. The study results can be used to evolve proposals for screening, surveillance and treatment plan of high -risk groups after attaining MDA termination. To stop further re-establishment of infection there is need to recognize residual microfilaremia. Residual microfilaremia can be detected by customized surveys along with pre-MDA monitoring and TAS (Transmission assessment survey).

\section{Acknowledgement: None}

\section{Conflict of Interest: None}

\section{Source of Funding: None}

\section{Ethical Approval: Approved}

\section{REFERENCES}

1. WHO (2017) Global programme to eliminate lymphatic filariasis: Progress report 2016. WHO Weekly Epidemiological Record 40: 589-608.

2. Simonsen PE, Mwakitalu ME. Urban lymphatic filariasis. Parasitol Res. 2013;112(1):35-44. https:// doi. org/ 10. 1007/ s00436- 012- 3226-x.
3. Ottesen EA. The global programme to eliminate lymphatic filariasis. Trop Med Int Health 2000;5:591-4.

4. Ottesen EA, Duke BOL, Karam M, Behbehani K. Strategies and tools for thecontrol/elimination of lymphatic filariasis. Bull World Health Organ 1997; 75:491-503.

5. Building partnerships for lymphatic filariasis - strategic plan. Geneva: WHO;1999.

6. Accelerated plan for elimination of lymphatic Filariasis, 2018, NVBDCP, Directorate General of Heaith Services, Ministry of Health and Family health care , Government of India

7. Cobbold TS. Discovery of the adult representative of microscopic filariae. Lancet. 1877;2:70-71

8. Brug SL. Filaria malayi, new species. Parasitic in man in the Malay Archipelago. Transactions of the $7^{\text {th }}$ Congress of the Far Eastern Association of Tropical Medicine. 1927;iii:279

9. Partono F, Aennis DT, Atmosoedjono S, et al. Brugia timori sp.n. (nematode: Filarioidea) from Flores Island, Indonesia. Journal of Parasitology. 1977;63:540-546

10. Agrawal V, Sashindran V. Lymphatic filariasis in India: problems, challenges and new initiatives. Med J Armed Forces India. 2006;62(4):359-62.

11. Ramaiah KD, Das PK, Michael E, Guyatt $\mathrm{H}$. The economic burden of lymphatic filariasis in India. Parasitol Today 2000; 16: 251-3.

12. Neglected tropical diseases: hidden successes, emerging opportunities.Geneva: WHO; 2006.

13. Susanta Kumar Ghosh* and Pradeep Kumar Srivastava A New Outlook in Lymphatic Filariasis Elimination in India DOI: http://dx.doi.org/10.5772/intechopen.92454

14. WHO. Lymphatic Filariasis. Geneva: WHO; 2020. Available from: https://www.who.int/news-room/factsheets/detail/lymphatic-filariasis

15. World Health Organization: Monitoring and epidemiological assessment of mass drug administration in the global programme to eliminate lymphatic filariasis: a manual for national elimination programmes. Geneva: World Health Organization; 2011.

16. World Health Organization: Lymphatic filariasis: a handbook of practical 
entomology for national lymphatic filariasis elimination programmes. Geneva: World Health Organization; 2013.

17. World Health Organization (2011) Global Programme to Eliminate Lymphatic Filariasis: progress report on mass drug administration, 2010. Wkly Epidemiol Rec 86: 377-388.

18. "District Dumka, Government of Jharkhand | The Land of Temples | India". Retrieved 30 December 2020.

19. Pani SP, Balakrishnan N, Srividya A, Bundy DAP, Grenfell BT. Clinical epidemiology of bancroftian filariasis: effect of age and gender. Trans $R$ Soc Trop Med Hyg 1991; 85: 260-4.
20. Sharma RVSN, Vallishayee RS, Mayurnath S,Narayanan PR, Radhamani MP, Tripathy SP.Prevalence survey of filariasis in two villages inChingleput district of Tamil Nadu. Indian J MedRes 1987; 85: 522-30.

21. Brabin L. Sex differentials in susceptibility to lymphatic filariasis and implications for maternal child immunity. Epidemiol Infect 1990; 105:335-53.

How to cite this article: Oraon V, Topno V. Lymphatic filariasis profile in Dumka district of Jharkhand, India. International Journal of Research and Review. 2021; 8(11): 364-369. DOI: https://doi.org/10.52403/ijrr.20211145 